\title{
TRIAZINES
}<smiles>CC(C)Nc1nc(Cl)nc(NC(C)C)n1</smiles>

Propazine<smiles>CCNc1nc(Cl)nc(NC(C)C)n1</smiles>

Atrazine<smiles>CCNc1nc(Cl)nc(NCC)n1</smiles><smiles>CCCCCCCCC(C)C</smiles><smiles>COc1nc(NC(C)C)nc(NC(C)C)n1</smiles>

\section{MALATHION AND METABOLITES}<smiles>CCOC(=O)CC(SP(=S)(OC)OC)C(=O)OCC</smiles>

Malathion<smiles>CCOC(=O)CC(SP(C)(=O)OC)C(=O)OCC</smiles>

Isomalathion<smiles>CCOC(=O)CC(SP(=O)(OC)OC)C(=O)OCC</smiles>

Oxomalathion

Figure 1S. Chemical Structures of analytes. 